\title{
Mechanism and Kinetics of Heterosynaptic Depression at a Cerebellar Synapse
}

\author{
Jeremy S. Dittman and Wade G. Regehr \\ Department of Neurobiology, Harvard Medical School, Boston, Massachusetts 02115
}

High levels of activity at a synapse can lead to spillover of neurotransmitter from the synaptic cleft. This extrasynaptic neurotransmitter can diffuse to neighboring synapses and modulate transmission via presynaptic receptors. We studied such modulation at the synapse between granule cells and Purkinje cells in rat cerebellar slices. Brief tetanic stimulation of granule cell parallel fibers activated inhibitory neurons, leading to a transient elevation of extracellular GABA, which in turn caused a short-lived heterosynaptic depression of the parallel fiber to Purkinje cell EPSC. Fluorometric calcium measurements revealed that this synaptic inhibition was associated with a decrease in presynaptic calcium influx. Heterosynaptic inhibition of synaptic currents and calcium influx was eliminated by an- tagonists of the $\mathrm{GABA}_{\mathrm{B}}$ receptor. The magnitude and time course of the depression of calcium influx were mimicked by the rapid release of an estimated $10 \mu \mathrm{M}$ GABA using the technique of flash photolysis. We found that inhibition of presynaptic calcium influx peaked within $300 \mathrm{msec}$ and decayed in $<3 \mathrm{sec}$ at $32^{\circ} \mathrm{C}$. These results indicate that presynaptic $\mathrm{GABA}_{\mathrm{B}}$ receptors can sense extrasynaptic GABA increases of several micromolar and that they rapidly regulate the release of neurotransmitter primarily by modulating voltage-gated calcium channels.

Key words: synaptic modulation; magnesium green; caged GABA; Purkinje cell; granule cell; paired-pulse facilitation; $G A B A_{B}$ receptor
Most presynaptic terminals in the mammalian CNS possess highaffinity metabotropic receptors that can be activated by chemical messengers such as GABA, glutamate, or adenosine (Starke, 1981; Nicoll et al., 1990). Synaptic strength is controlled in part by the occupancy of these receptors, which in turn is set by the extracellular concentrations of their agonists. In some cases, tonic levels are sufficient to partially activate the receptors (Lerma et al., 1986), but synaptic activity can increase receptor occupancy further by transiently elevating neuromodulator concentration. After release, transmitter molecules can act homosynaptically and bind to presynaptic autoreceptors (Deisz and Prince, 1989; Davies et al., 1990), or they can act heterosynaptically by diff using to nearby terminals (Fuxe and Agnati, 1991; Isaacson et al., 1993).

Studies of presynaptic metabotropic receptors typically have focused on steady-state applications of agonists (Scholz and Miller, 1991; Yawo and Chuhma, 1993; Wu and Saggau, 1994; Dittman and Regehr, 1996). However, a study of heterosynaptic depression in the hippocampus revealed the importance of kinetics in determining the magnitude and the time course of presynaptic inhibition under more realistic conditions (Isaacson et al., 1993). They found that extrasynaptic GABA acted through $\mathrm{GABA}_{\mathrm{B}}$ receptors to inhibit rapidly and transiently the glutamatergic CA3 to CA1 synapse.

In addition to factors controlling the extracellular modulator signal, the kinetics of the modulatory system will help to determine the dynamics of presynaptic modulation. The time course of modulation of ion channels has been investigated in the soma of

Received Aug. 11 1997; revised Sept. 18, 1997; accepted Sept. 22, 1997.

This work was supported by National Institutes of Health Grant R01-NS32405-01. We thank Pradeep Atluri, Chinfei Chen, Matthew Friedman, Bruce Peters, and Bernardo Sabatini for comments on this manuscript. Ciba-Geigy generously provided CGP35348 and CGP55845A for these experiments.

Correspondence should be addressed to Dr. Wade G. Regehr, Department of Neurobiology, Harvard Medical School, 220 Longwood Avenue, Boston, MA 02115. Copyright (C) 1997 Society for Neuroscience $0270-6474 / 97 / 179048-12 \$ 05.00 / 0$ acutely dissociated and cultured neurons (Jones, 1991; Sahara and Westbrook, 1993; Sodickson and Bean, 1996; Zhou et al., 1997). It has also been possible to compare the kinetics of presynaptic modulation of synaptic transmission to modulation of somatic calcium channels in cultured hippocampal cells (Pfrieger et al., 1994). These experimental preparations benefit from the ability to rapidly and precisely control agonist concentrations. However, it has been difficult to perform similar kinetic studies in more intact preparations, such as brain slices, in which rapid solution exchange is not possible.

Here we investigate the kinetics of presynaptic modulation at the parallel fiber to Purkinje cell synapse in rat cerebellar slices. We have shown previously that the steady-state application of the $\mathrm{GABA}_{\mathrm{B}}$ receptor agonist baclofen decreases the strength of this synapse primarily by modulating presynaptic calcium channels coupled to $\mathrm{GABA}_{\mathrm{B}}$ receptors (Dittman and Regehr, 1996). To study the kinetics of presynaptic inhibition, we took two approaches to produce rapid transients of extrasynaptic GABA. First, we stimulated inhibitory interneurons and characterized the resulting heterosynaptic depression at parallel fiber presynaptic terminals. Second, we used flash photolysis of caged GABA to locally increase extrasynaptic GABA to known concentrations. Presynaptic inhibition was assessed by measuring the resulting changes in presynaptic calcium influx and postsynaptic currents. This combination of approaches provided insights into both the GABA signal responsible for presynaptic inhibition at this synapse and the factors contributing to the kinetics of presynaptic inhibition.

\section{MATERIALS AND METHODS}

Synaptic physiology. Transverse slices (300 $\mu \mathrm{m}$ thick) were cut from the cerebellar vermis of 9- to 15 -d-old Sprague Dawley rats. Slices were superfused with an external solution containing (in $\mathrm{mM}$ ): $125 \mathrm{NaCl}, 2.5$ $\mathrm{KCl}, 2 \mathrm{CaCl}_{2}, 1 \mathrm{MgCl}_{2}, 26 \mathrm{NaHCO}_{3}, 1.25 \mathrm{NaH}_{2} \mathrm{PO}_{4}$, and 25 glucose, bubbled with $95 \% \mathrm{O}_{2} / 5 \% \mathrm{CO}_{2}$. Flow rates were maintained at 1-2 $\mathrm{ml} / \mathrm{min}$ at $24^{\circ} \mathrm{C}$ and $5-8 \mathrm{ml} / \mathrm{min}$ at $32^{\circ} \mathrm{C}$. Bicuculline $(20 \mu \mathrm{M})$ was added 
to the external solution to suppress synaptic currents mediated by $\mathrm{GABA}_{\mathrm{A}}$ receptors.

Whole-cell recordings of Purkinje cells were obtained as described previously (Mintz et al., 1995) using 1-2 M $\Omega$ glass pipettes containing an internal solution of (in mM): $35 \mathrm{CsF}, 100 \mathrm{CsCl}, 10 \mathrm{EGTA}, 10 \mathrm{HEPES}$, and $0.2 \mathrm{D} 600$, adjusted to $\mathrm{pH} 7.2$ with $\mathrm{CsOH}$. The access resistance $(<5$ $\mathrm{M} \Omega$ after series resistance compensation) and leak current $(-20$ to -200 pA) were monitored continuously. Experiments were rejected if either parameter varied significantly during recording.

Fluorometric detection of calcium transients. Cerebellar granule cell parallel fibers from 14- to 20-d-old rats were labeled with a high-pressure stream of magnesium green (Molecular Probes, Eugene, OR) as described previously (Regehr and Tank, 1991; Regehr and Atluri, 1995). Fluorescence was measured with a photodiode, and the output was filtered at 500 $\mathrm{Hz}$ with an 8-pole Bessel filter (Frequency Devices) and sampled at $2.5 \mathrm{kHz}$ with a 16-bit analog-to-digital converter (Instrutech, Great Neck, NY) using PULSE CONTROL software (Herrington and Bookman, 1995). The $\Delta F / F$ ratio was calculated and used as a linear measure of presynaptic calcium influx as established previously (Regehr and Atluri, 1995).

Induction of heterosynaptic depression. For electrophysiological and fluorometric assays of heterosynaptic depression, two stimulus electrodes were placed in the molecular layer. One electrode was used to stimulate parallel fibers in a test pathway, and the other was used to deliver a 10 pulse, $100 \mathrm{~Hz}$ tetanus in a nonoverlapping pathway. To confirm that the two electrodes stimulated distinct sets of parallel fibers, the electrodes were positioned such that stimulation of one pathway did not produce any detectable paired-pulse facilitation in the other pathway. In fluorometric detection experiments, the tetanus electrode was positioned so that the tetanus did not elicit a fluorescence transient at the recording site.

Calibration of photolytic conversion reactions. Photolysis of $\gamma$ aminobutyric acid, $\alpha$-carboxy-2-nitrobenzyl ester (CNB-caged GABA Molecular Probes Cat\# A-7110) was performed with a UV flashlamp (Cairn) coupled to the epifluorescence port of a Zeiss Axioskop by a liquid light guide. Because a proton is generated along with free GABA when a molecule of CNB-caged GABA undergoes photolysis, the change in proton concentration after photolysis was used to estimate the amount of free GABA released after a brief UV flash. A similar approach has been used previously with other caged compounds (Walker et al., 1988). Cuvette calibrations of photolysis were performed by focusing the UV flash through an objective (Olympus, $40 \times$ ) to a $300 \mu \mathrm{m}$ spot within a glass cuvette. Cuvettes were filled with a solution containing (in mM) 120 $\mathrm{NaCl}, 4 \mathrm{HEPES}, 8 \mathrm{MgCl}_{2}$, and $1.5 \mathrm{CNB}$-caged GABA at $\mathrm{pH} 7.1-7.4$ The pH-sensitive ratiometric fluorophore 5,6-carboxy-SNARF-1 (200 $\mu \mathrm{M})$ was included to monitor changes in proton concentration after photolysis. The preparation could be illuminated simultaneously by the flashlamp and a shutter-gated light source with a 510DF10, combined with a custom-built adaptor using a 400 DRLP dichroic mirror. A 540 DRLP dichroic mirror was used in the fluorescence path with an OG550 long-pass filter. SNARF-1 fluorescence ratios were measured in an epifluorescence configuration using two photodiodes to detect the emission fluorescence changes both in the 550-620 nm band and at wavelengths greater than $630 \mathrm{~nm}$. A 620 DRLP dichroic mirror was used to split the emission fluorescence between the photodiodes. The output of the photodiodes was filtered at $500 \mathrm{~Hz}$ and sampled at $2.5 \mathrm{kHz}$. Figure $1 A$ (top) shows the emission fluorescence ratio change in response to single flashes from the UV flashlamp. Free proton concentration was estimated using the following ratiometric relation:

$$
\left[\mathrm{H}^{+}\right]_{\text {Free }}=K_{\text {SNARF }}\left(\frac{R-R_{\min }}{R_{\max }-R}\right) \frac{F_{\text {base }}\left(\lambda_{2}\right)}{F_{\text {acid }}\left(\lambda_{2}\right)} \quad R=\frac{F\left(\lambda_{1}\right)}{F\left(\lambda_{2}\right)},
$$

where $\lambda_{1}=550-620 \mathrm{~nm}, \lambda_{2}>630 \mathrm{~nm}, F_{\text {base }}\left(\lambda_{2}\right)$ was measured at $\mathrm{pH} 9.5$, and $F_{\text {acid }}\left(\lambda_{2}\right)$ was measured at $\mathrm{pH}$. The calculated $\mathrm{pH}$ change is shown in Figure $1 \mathrm{~A}$ (middle). The change in total proton concentration was calculated using the following equation:

$$
\begin{aligned}
& {\left[\mathrm{H}^{+}\right]_{\text {Total }}=\left[\mathrm{H}^{+}\right]_{\text {Free }}\left(1+\frac{[\mathrm{HEPES}]_{\text {Total }}}{K_{\mathrm{HEPES}}+\left[\mathrm{H}^{+}\right]_{\text {Free }}}+\right.} \\
&\left.\frac{[\mathrm{SNARF}]_{\text {Total }}}{K_{\mathrm{SNARF}}+\left[\mathrm{H}^{+}\right]_{\text {Free }}}+\frac{[\mathrm{GABA}]_{\text {Total }}}{K_{\mathrm{GABA}}+\left[\mathrm{H}^{+}\right]_{\text {Free }}}\right),
\end{aligned}
$$

with $K_{\mathrm{HEPES}}=10^{-7.5}, K_{\mathrm{SNARF}}=10^{-7.5}$, and $K_{\mathrm{GABA}}=10^{-10.6}$. Assuming a 1:1 ratio between the number of protons released and the amount of uncaged GABA, the free GABA was calculated just after a UV flash
(Fig. A, bottom). Flash output energy was controlled by changing the amount of capacitance charged with a fixed voltage $(300 \mathrm{~V})$ and then discharged across the flash bulb. By varying the capacitance from 0.5 to $4 \mathrm{mF}$, a family of photolysis transients was recorded and converted into percent yield by dividing the peak amount of estimated free GABA by the total CNB-caged GABA in the cuvette, as shown in Figure $1 B$. At maximal flash output, the conversion yield was estimated to be $7.7 \pm$ $0.2 \%$ (mean \pm SEM, $n=8$ ). Additional experiments were performed with CNB-caged glutamate ( $\alpha$-carboxy-2-nitrobenzyl ester, Molecular Probes Cat\# A-7055), and similar photolytic yields were observed.

Local pressure application of caged GABA. Caged GABA was applied locally to minimize the amount used. This method of application has additional advantages: (1) it reduces uncaging outside the plane of focus; (2) the flow helped to clear uncaged neurotransmitter; and (3) absorbance of UV light between the objective and the slice by caged GABA is avoided. Caged GABA (180 $\mu \mathrm{M}$ in external solution) was applied to the surface of a slice through a glass pipette with a tip diameter of $20-25 \mu \mathrm{m}$ at flow rates of $0.5-2 \mu \mathrm{l} / \mathrm{min}$. A fluorescent indicator sometimes was included in the pipette to determine the spatial extent of the flow. The UV illumination spot $(10-100 \mu \mathrm{m}$ in diameter) was centered on the region of interest within the plume of caged GABA flow.

Divergence of the pipette solution away from the tip resulted in a dilution of the pipette contents, as depicted in the cartoon in Figure $2 A$. Experiments were performed to estimate the magnitude of this dilution and thereby the concentration of caged GABA. For experiments in which calcium influx was detected optically, parallel fibers were filled with the calcium-sensitive indicator magnesium green and stimulated with a monopolar electrode. Stimulus-evoked changes in fluorescence were measured in a $50-\mu \mathrm{m}$-diameter region near the surface of the slice in the molecular layer, as described previously (Regehr and Atluri, 1995). A pipette containing $0 \mathrm{CaCl}_{2}$ and $3 \mathrm{mM} \mathrm{MgCl}_{2}$ was brought near the fluorescence spot, and a steady flow of this solution substantially decreased the calcium influx, as shown in Figure $2 B$. This decrease was compared with the external calcium dose-response curve determined in Mintz et al. (1995) to estimate the effective concentration of external calcium within the fluorescence spot. It was found to be $0.37 \pm 0.08 \mathrm{~mm}$ (mean \pm SEM, $n=4$ ). Thus, in these experiments the pipette contents are diluted to $82 \pm 4 \%$ of their original concentration.

Experiments were also performed to estimate the dilution of pipette contents for experiments in which EPSCs were monitored. Parallel fiber to Purkinje cell EPSCs were recorded, and a pipette containing $150 \mu \mathrm{M}$ kynurenic acid, a low-affinity competitive AMPA receptor antagonist, was placed near the Purkinje cell dendrites in the molecular layer. When delivered from a pipette, kynurenic acid was less effective than when it was bath-applied (Fig. 2C). We used this decrease to estimate the effective concentration of the pipette contents using the formula 100(1 $R_{\mathrm{p}} / R_{\mathrm{b}}$ ), where $R_{\mathrm{p}}$ and $R_{\mathrm{b}}$ are, respectively, the percent reductions of the EPSC when kynurenate is applied with a pipette and in the bath (this is only valid when [kynurenate] $<K_{\mathrm{d}}$ to avoid nonlinearities associated with saturation of AMPA receptors). When averaged over the depth of the Purkinje cell dendritic arborization, the pipette contents were diluted to $45 \pm 5 \%$ of their original concentration (mean \pm SEM, $n=3$ ). The greater degree of dilution in these experiments likely reflects the fact that, during extracellular stimulation, many of the activated synapses are located on Purkinje cell dendrites extending hundreds of micrometers within the slice. Presumably, synapses deeper in the slice were exposed to lower concentrations of kynurenic acid.

We concluded that local application of compounds via pipette is reasonably effective for measurements restricted to the surface of the slice, such as calcium detection. However, this technique is less effective when recording synaptic currents because the pipette solution is significantly diluted deeper in the slice, where many of the synaptic contacts onto Purkinje cells are made.

Calcium measurements with caged GABA. The effects of uncaged GABA on presynaptic calcium influx are illustrated in Figure 3 . We applied $180 \mu \mathrm{M}$ caged GABA via pipette to a region of parallel fibers filled with magnesium green in the presence of $20 \mu \mathrm{M}$ bicuculline. Stimulus-evoked fluorescence transients were measured $8 \mathrm{sec}$ before and $1 \mathrm{sec}$ after exposure to a brief UV flash, and a reduction in the calcium influx was observed (Fig. 3, inset). By varying the energy of the flashlamp, a dose-response curve for reduction of calcium influx was generated. Figure $3 B$ shows the average of a set of experiments performed at 22 and $32^{\circ} \mathrm{C}$. The free GABA concentration was estimated by correcting the concentration of caged GABA in the pipette for dilution and by using the uncaging yield measurements from the cuvette $\mathrm{pH}$ calibrations described 
A
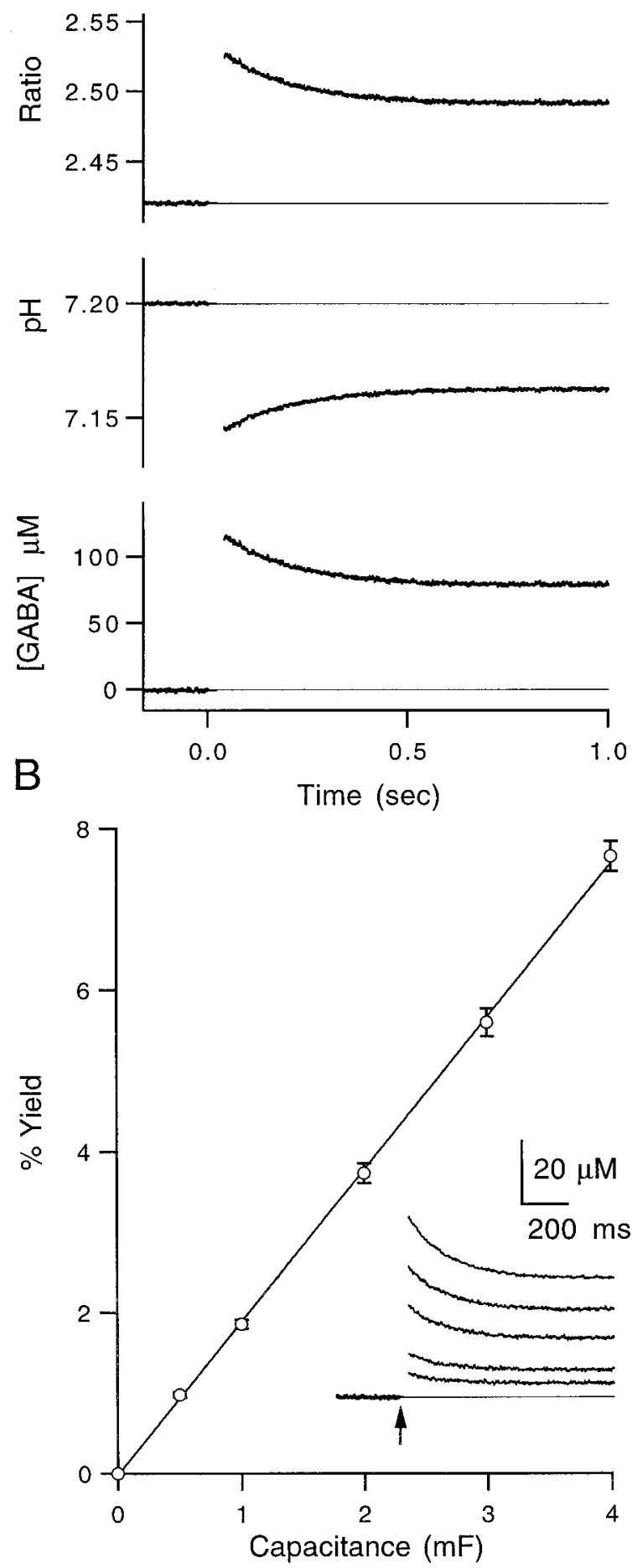

Figure 1. Photolysis calibrations using $\mathrm{pH}$-sensitive fluorophores. A, Top, Ratio of two SNARF emission wavelengths before and after UV flash at $t=$ 0 . Middle, Ratiometric estimate of $\mathrm{pH}$ after UV flash as described in Materials and Methods. Bottom, Calculated concentration of free GABA uncaged as described in Materials and Methods. All traces are averages of three trials. $B$, Average of eight calibration experiments showing the amount of uncaging at a variety of flashlamp output levels. Data were fit to a line with a slope of $1.9 \% / \mathrm{mF}$ (data points are mean $\pm \mathrm{SEM}, n=8$ ). Inset, Calculated free GABA concentration after UV flash at five capacitance levels for a representative experiment. Arrow marks the time of flash. Traces are averages of three trials. above (see Fig. 1). We observed that concentrations of caged GABA higher than $180 \mu \mathrm{M}$ resulted in a decrease in calcium influx and in the Purkinje cell EPSC magnitude during application. This is consistent with the previous conversion of $\sim 1 \%$ of the caged GABA (Gee et al., 1994). To avoid working under conditions of significant steady-state inhibition, all experiments were performed with $180 \mu \mathrm{M}$ caged GABA.

The 5,6-carboxy-SNARF, caged compounds, CGP35348, and CGP55845A were stored at $-80^{\circ} \mathrm{C}$ at stock concentrations of (in mM) 2, 15,50 , and 10 , respectively, in deionized water and brought to their final concentrations immediately before use. Exposure of the caged compounds to light was minimized to prevent excessive photolysis.

\section{RESULTS}

We performed a series of experiments to determine whether GABA released during high levels of activity can diffuse to neighboring terminals and modulate synaptic transmission in rat cerebellar slices (Fig. 4A). To understand how activation of glutamatergic parallel fibers can elevate extracellular GABA levels, it is necessary to consider the anatomy of the cerebellar cortex. In addition to contacting Purkinje cells, parallel fibers excite other cell types, including stellate cells and basket cells (Fig. 4A, left). These small inhibitory neurons are present at high density, with an estimated 16-17 stellate cells present for each Purkinje cell (Ito, 1984). They have rather compact dendritic trees, extend axons for several hundred micrometers, and make GABAergic synaptic contacts throughout the molecular layer. Stimulation of parallel fibers will excite these interneurons, leading to GABA release. The released GABA can act locally, activating low-affinity $\mathrm{GABA}_{\mathrm{A}}$ receptors at a high concentration, or it can diffuse from the synaptic cleft and activate distant highaffinity receptors, such as $\mathrm{GABA}_{\mathrm{B}}$ receptors at much lower concentrations (Mody et al., 1994) (Fig. 4A, right).

\section{Post-tetanic heterosynaptic depression of Purkinje cell EPSCs}

In our experiments, EPSCs produced by stimulation of granule cell parallel fibers were recorded in whole-cell voltage-clamp mode from cerebellar Purkinje cells. A second stimulus electrode was positioned within the molecular layer to test for heterosynaptic depression, as shown schematically in Figure $4 A$. A brief tetanus $(10$ pulses at $100 \mathrm{~Hz}$ ) applied through electrode $(S 2)$ resulted in a transient reduction in the magnitude of EPSCs evoked $400 \mathrm{msec}$ later from the test electrode ( $S 1)$, as shown in Figure $4 B$. This inhibition of currents evoked by S1 (EPSC ${ }_{1}$ ) was heterosynaptic, because the two electrodes stimulated nonoverlapping populations of parallel fibers. In 10 experiments, the competitive $\mathrm{GABA}_{\mathrm{B}}$ receptor antagonist CGP35348 (Olpe et al., 1990) completely eliminated the heterosynaptic depression in a reversible manner at 100 $\mu \mathrm{M}$, supporting the hypothesis that GABA mediates the depression by activating $\mathrm{GABA}_{\mathrm{B}}$ receptors (Fig. $4 C$ ). The high-affinity $\mathrm{GABA}_{\mathrm{B}}$ receptor antagonist CGP55845A (Davies et al., 1993) prevented heterosynaptic depression at a concentration of $1 \mu \mathrm{M}$ (data not shown), although it proved difficult to reverse the occlusion completely. Presumably, the extrasynaptic GABA resulted from spillover at synaptic clefts of interneurons, as has been shown for hippocampal synapses (Isaacson et al., 1993).

We next determined the time course of heterosynaptic depression. A pair of test pulses separated by $30 \mathrm{msec}$ was used to monitor paired-pulse facilitation (PPF) during the heterosynaptic depression (Fig. 5A). The effect of tetanic stimulation of S2 on $\mathrm{EPSC}_{1}$ after a $500 \mathrm{msec}$ delay is shown in Figure $5 B$. By scaling pre- and post-tetanus EPSCs, it is apparent that the magnitude of PPF increased slightly after stimulation (Fig. $5 C$ ). Such increases in PPF in concert with depression of the $\mathrm{EPSC}_{1}$ magnitude 

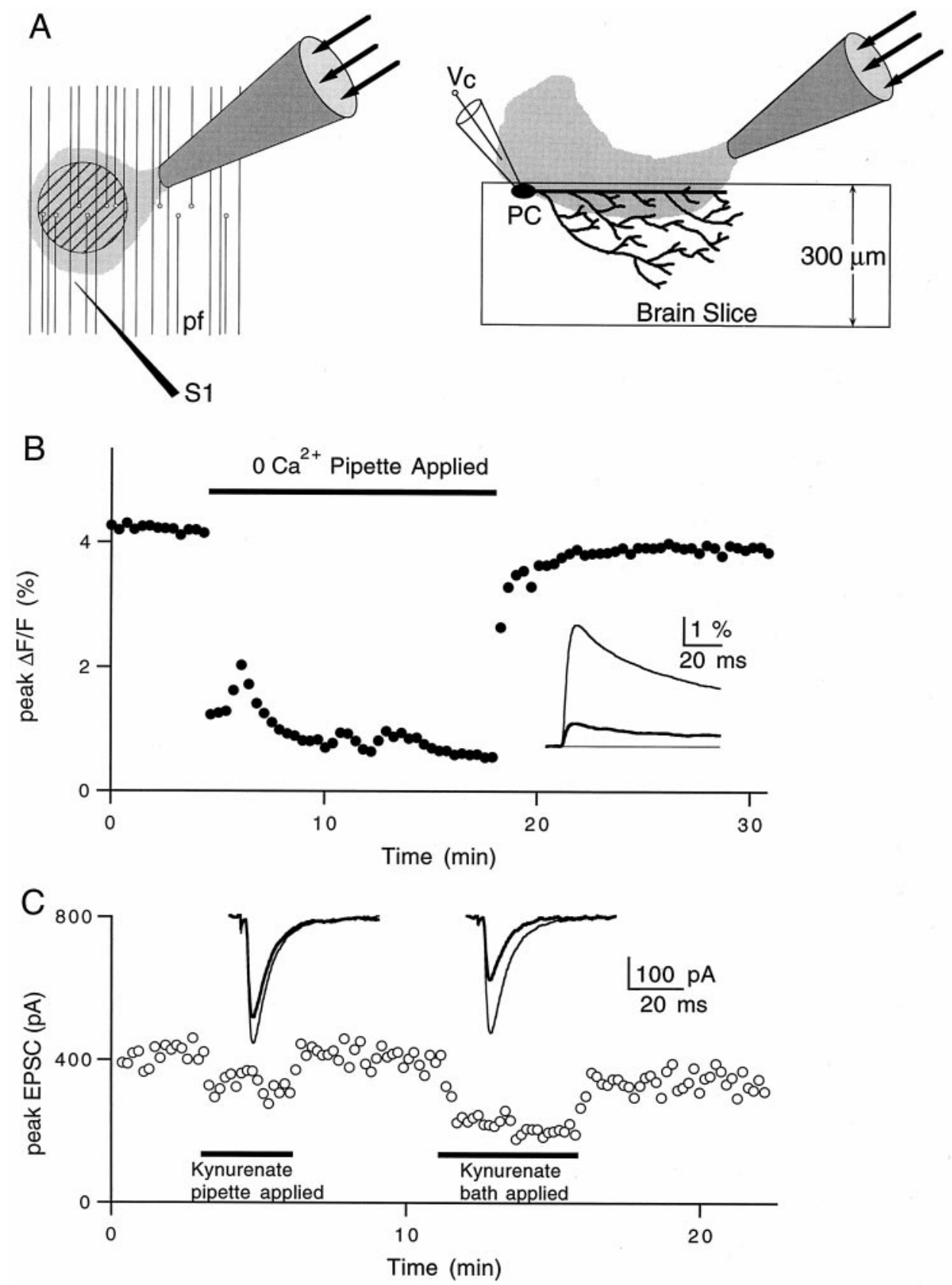

Figure 2. Local pressure application and dilution estimates. $A$, Schematic illustrating the slice regions exposed to the pipette solution. Hatched circle in the left panel represents the region of parallel fibers $(p f)$ where calcium measurements are taken. $S 1$ is the stimulus electrode. The right panel illustrates a brain slice in cross section during voltage-clamp $(V c)$ recording from a Purkinje cell $(P C) . B$, Representative experiment showing the effects of local application of $0 \mathrm{Ca}^{2+}$ solution on total presynaptic calcium influx. Inset, Averages of 10-15 traces in control (thin line) and $0 \mathrm{Ca}^{2+}$ (thick line) conditions. $C$, Representative experiment showing the effects of local versus bath-applied kynurenate (150 $\mu \mathrm{M})$ on Purkinje cell EPSC amplitudes. Inset, Averages of 10-15 traces in control (thin lines) and during exposure to kynurenate (thick lines) for pipette application (left) and bath application (right). typically are associated with decreases in the probability of transmitter release (Zucker, 1989).

The time course of heterosynaptic depression and increase in PPF were determined by measuring the post-tetanus pair of EPSCs while varying the delay between the tetanus and test pulse. Depression was measured between $100 \mathrm{msec}$ and $3 \mathrm{sec}$ after a tetanus was delivered. Synaptic depression and the increase in PPF had similar time courses (Fig. 5D). CGP35348 eliminated the depression and change in PPF at all durations tested (data not shown). The apparent delay between depression and PPF is likely to be the result of increasing depression during the paired-pulse protocol. As a result of the rapid increase in depression, the second EPSC will be slightly reduced in amplitude, resulting in an underestimate of PPF at early time points.

\section{Post-tetanic heterosynaptic depression of presynaptic calcium influx}

The effect on PPF suggested a presynaptic locus for heterosynaptic depression. To define further the target of heterosynaptic depression, we determined the effect of the tetanus protocol on presynaptic calcium influx. We have shown previously that the major mechanism by which steady-state activation of $\mathrm{GABA}_{\mathrm{B}}$ receptors inhibits this synapse is via reduction in presynaptic calcium influx (Dittman and Regehr, 1996). We used a similar optical approach in this study (see Materials and Methods). Two stimulus electrodes were positioned in the molecular layer, as shown in Figure $6 A$. A brief tetanus of S2 reduced the influx of calcium produced by S1 (Fig. $6 B$ ). In seven experiments, this post-tetanic reduction in presynaptic calcium influx was blocked completely and reversibly by CGP35348, as shown in Figure $6 C$. 


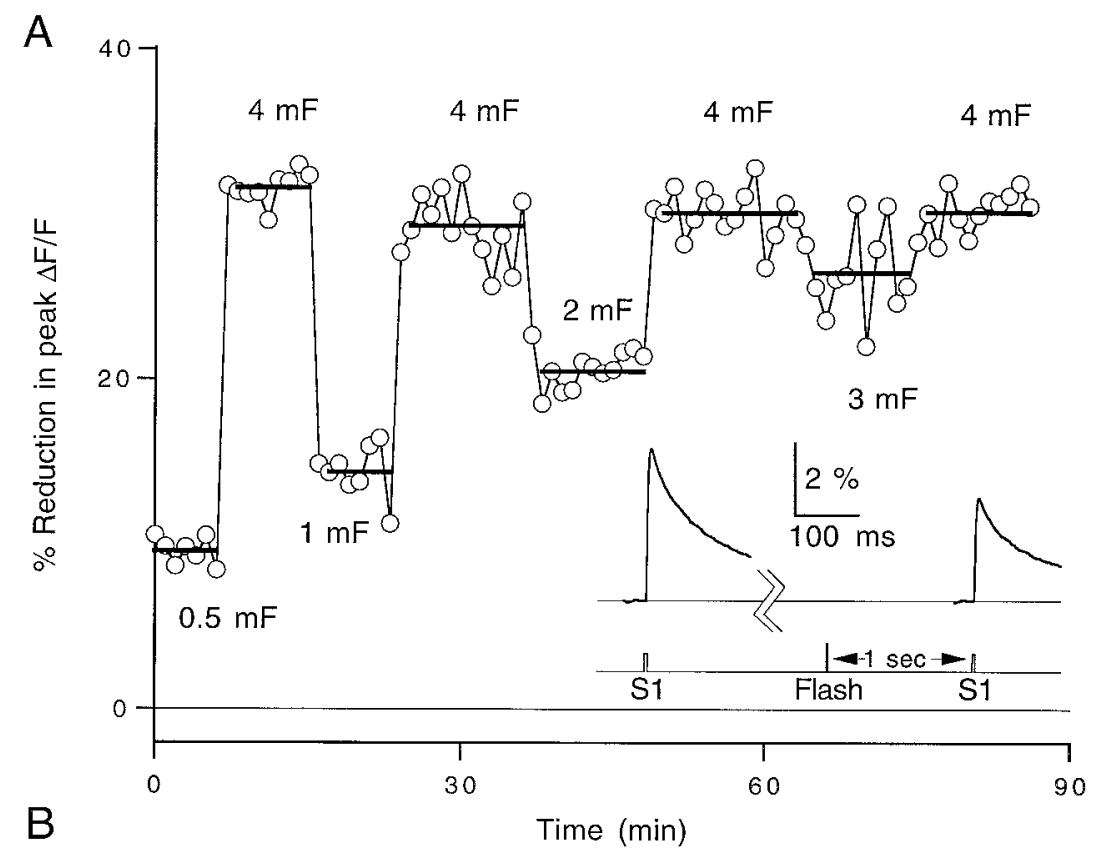

Figure 3. Dependence of reduction in presynaptic calcium influx on the concentration of uncaged GABA. $A$, Representative experiment showing the effect of uncaged GABA on presynaptic calcium influx at $22^{\circ} \mathrm{C}$ at five flash output levels. Each data point represents the percentage decrease in the peak magnesium green $\Delta F / F$ transient elicited $1 \mathrm{sec}$ after a $U V$ flash relative to a control $\Delta F / F$ transient elicited $8 \mathrm{sec}$ before the flash. Flash energy is indicated on the graph as the amount of capacitance charged at $300 \mathrm{~V}$. The bars represent the average reduction at the indicated capacitance value. Inset, Average of 10 fluorescence traces taken before and after a flash at 4 $\mathrm{mF}$. B, Averages of three experiments performed at $22^{\circ} \mathrm{C}$ (open circles) and three experiments at $32^{\circ} \mathrm{C}$ ( filled circles). Data points represent the mean \pm SEM. Data were normalized to the percent reduction in peak $\Delta F / F$ at $4 \mathrm{mF}$ in each experiment and fit to a logistic equation of the form: $\%$ Decrease $=100 /\left(1+\mathrm{IC}_{50} /[\mathrm{GABA}]\right)$, where $\mathrm{IC}_{50}$ $=7.1 \mu \mathrm{M}$ at $22^{\circ} \mathrm{C}$ and $10.3 \mu \mathrm{M}$ at $32^{\circ} \mathrm{C}$. The free GABA concentration scale at the bottom of the graph was calculated as explained in the text.

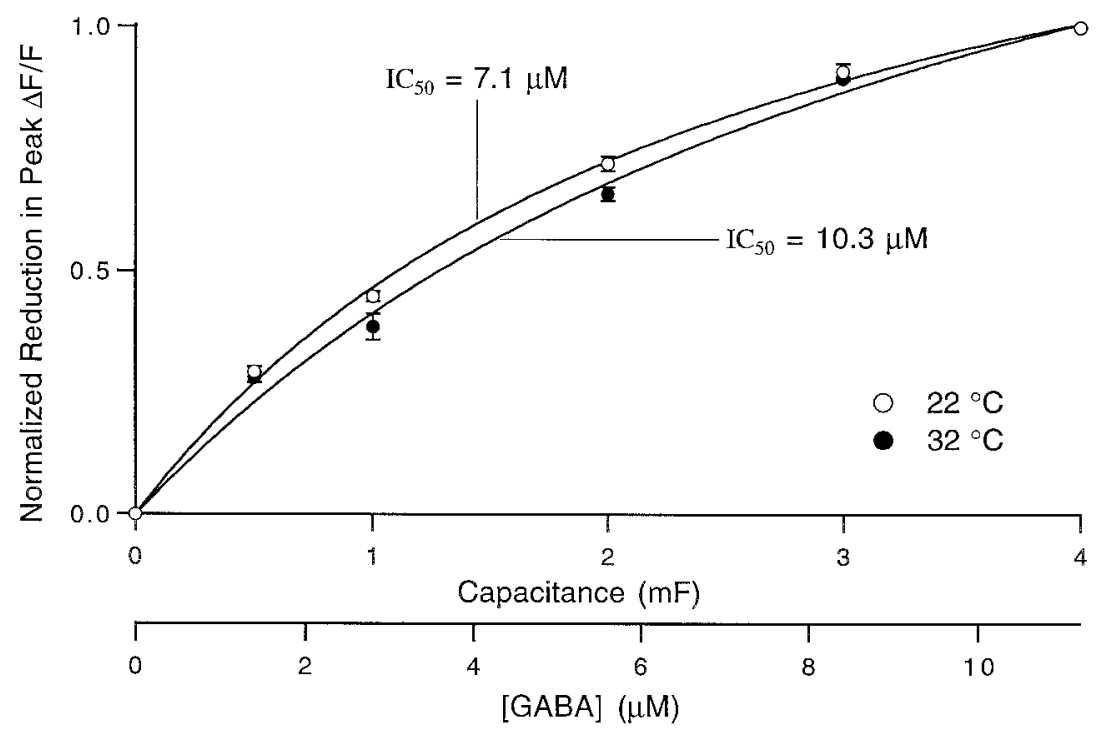

The time course of inhibition of calcium influx after a brief tetanus is shown in Figure $7 B$ for a representative experiment. The stimulus protocol is depicted in Figure $7 A$. CGP35348 blocked the reduction in calcium influx at all time points tested (data not shown). The post-tetanic reduction was also prevented by the glutamate receptor antagonists aminophosphonovalerate and 6-cyano-7-nitroquinoxaline-2,3-dione when the tetanus electrode was placed far from the measurement site $(300-500 \mu \mathrm{m})$, but not when the electrode was placed within $50 \mu \mathrm{m}$ of the site (data not shown). This suggests that when the tetanus electrode is far from the recording site, local interneurons are stimulated disynaptically via parallel fibers, whereas inhibitory neurons are stimulated directly when S2 is near the recording site.

Summaries of the time courses of reduction in EPSC amplitude and presynaptic calcium influx are shown in Figure 8. All experiments were performed at $32-33^{\circ} \mathrm{C}$. The transient reduction in synaptic strength decayed with a similar time course to the re- duction in presynaptic calcium $\left(\tau_{\text {decay }}, 1.0 \mathrm{vs} 1.1 \mathrm{sec}\right)$. The suppression of synaptic currents, however, was consistently more pronounced $(\sim 40 \%)$ than the corresponding reduction in calcium influx $(\sim 25 \%)$. These results are consistent with a supralinear relationship between presynaptic calcium influx and EPSC magnitude at this synapse (see Discussion).

\section{Presynaptic inhibition produced by photolysis of caged GABA}

A number of questions remain regarding heterosynaptic depression. Does it result from a few boutons experiencing high concentrations of GABA, or from many boutons sensing diffuse levels of GABA? Does the time course of heterosynaptic depression reflect diffusion and reuptake of GABA, or is it limited by the intrinsic kinetics of the signal transduction process within presynaptic terminals? To address these questions, we used flash photolysis of caged GABA to provide rapid application of GABA 

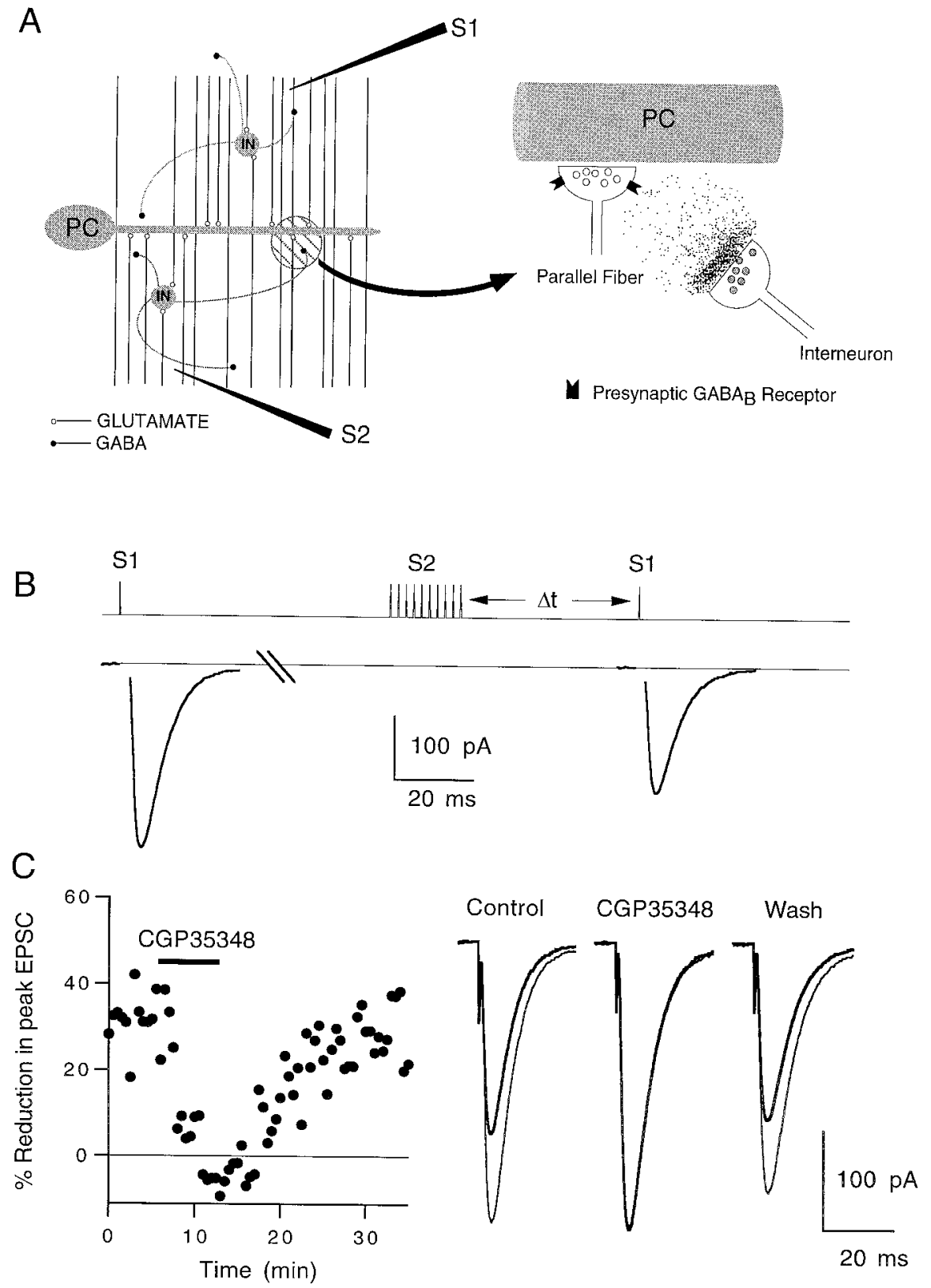

Figure 4. Heterosynaptic reduction in parallel fiber to Purkinje cell EPSC magnitude. $A$, Cartoon showing the GABA released by interneurons (IN) in the molecular layer diff using to nearby parallel fiber presynaptic terminals and binding to $\mathrm{GABA}_{\mathrm{B}}$ receptors (right panel). Extracellular stimulus electrodes were placed in the molecular layer as shown in the left panel. $S 1$ is the test electrode, and $S 2$ is the tetanus electrode. $P C$, Purkinje cell. $B$, Pulse protocol for a representative experiment showing the effects of a 10 pulse, $100 \mathrm{~Hz}$ tetanus delivered by electrode S2 on the size of the EPSC elicited by electrode S1. The control pulse was given $5 \mathrm{sec}$ before the tetanus. The test pulse was given $400 \mathrm{msec}$ after the tetanus. $C$, Effect of 100 $\mu \mathrm{M}$ CGP35348 on heterosynaptic depression assayed $400 \mathrm{msec}$ after the tetanus (left panel). Traces in the right panel are averages of 10 trials. The control EPSC (thin line) and post-tetanus EPSC (thick line) are superimposed. EPSCs were recorded at $-20 \mathrm{mV} . T=33^{\circ} \mathrm{C}$. within a small region of the brain slice (see Materials and Methods). The schematic in Figure $9 A$ depicts the arrangement of pipettes during uncaging experiments. A small pipette was placed near the slice surface, and a steady stream of caged GABA was delivered by applying a constant positive pressure to the pipette. Near the tip of the pipette, a 10 - to $50-\mu \mathrm{m}$-diameter region was illuminated with a brief $(<1 \mathrm{msec})$ pulse of UV light from a flashlamp to release a pulse of free GABA within the slice. Stimulus-evoked fluorescence transients from the same region were measured before and immediately after the flash (Fig. 9Ba) to assess the effects of GABA on calcium influx (Fig. 9Bb). In separate experiments, a similar arrangement was used to measure the effects of uncaged GABA on stimulus-evoked Purkinje cell EPSCs, as shown in Figure 9Bc. No modulation was observed in either presynaptic calcium influx or EPSC magnitude in the absence of caged GABA, demonstrating that the UV flash alone had no effect. To control for possible bioactivity of other uncaging products and small $\mathrm{pH}$ changes that occur after photolysis, CNBcaged glutamate was used at the same concentration. Although the uncaging as measured by $\mathrm{pH}$ calibrations was identical to caged GABA, caged glutamate had no effect on presynaptic calcium influx. It has been reported that the mGluR4 agonist L-AP4 causes a small reduction in synaptic transmission at this synapse (Pekhletski et al., 1996), although it is not clear whether this inhibition was caused by reduction in presynaptic calcium influx. Because we did not observe a reduction in calcium influx, we concluded that either glutamate does not inhibit synaptic transmission via voltage-gated calcium channels at this synapse or, alternatively, the rapid applications of $\sim 10 \mu \mathrm{M}$ glutamate used here were insufficient to inhibit presynaptic calcium influx. As a final control, $100 \mu \mathrm{M}$ CGP35348 occluded the flash-induced reduction in calcium influx, establishing that the uncaged GABA was acting through $\mathrm{GABA}_{\mathrm{B}}$ receptors (data not shown).

As discussed in Materials and Methods, it was difficult to access 
A

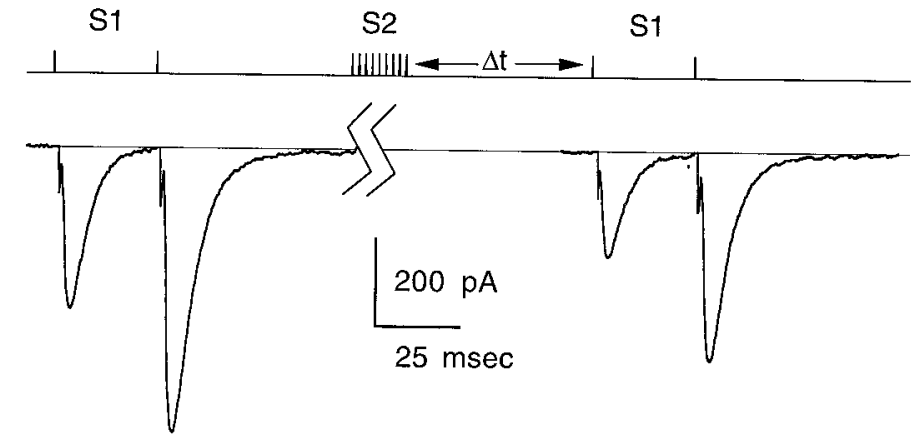

B

$\Delta \mathrm{t}=500 \mathrm{~ms}$

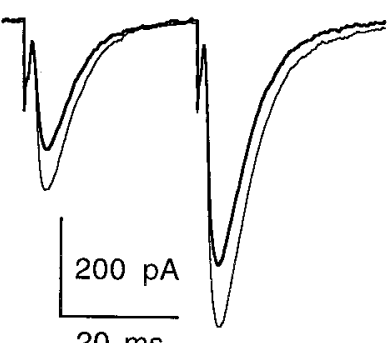

$20 \mathrm{~ms}$

C
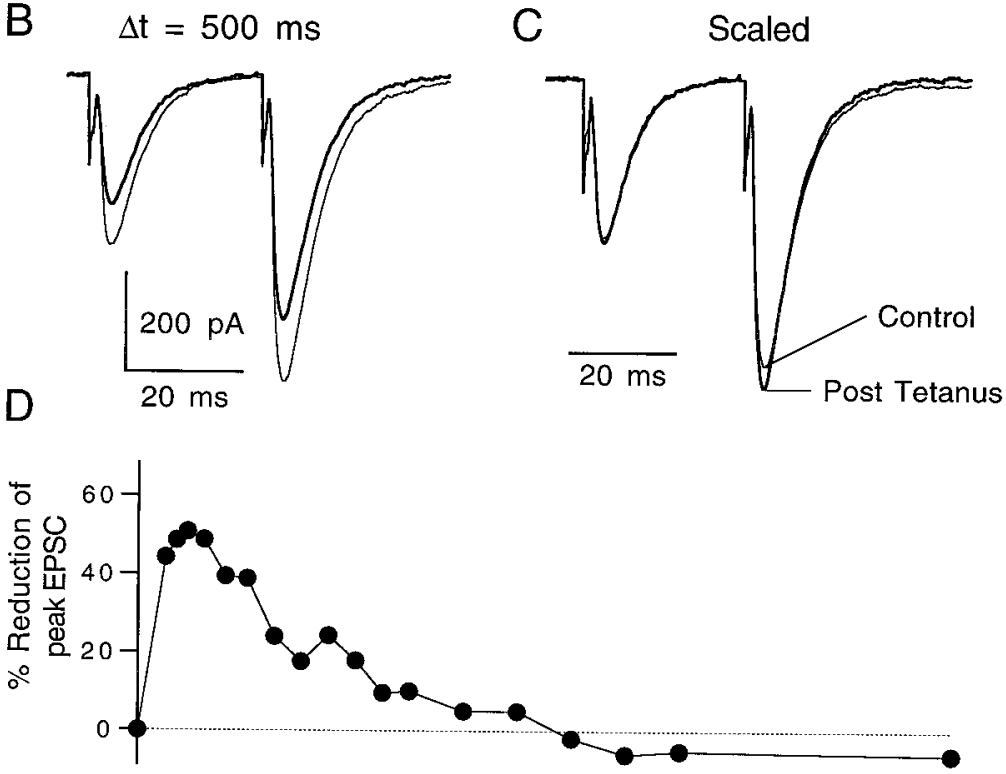

Figure 5. Time course of heterosynaptic depression. A, Pulse protocol for a representative experiment showing the effects of a 10 pulse, $100 \mathrm{~Hz}$ tetanus on a pair of test pulses given 30 msec apart. The control pair was elicited $10 \mathrm{sec}$ before the tetanus, and the test pair was taken $400 \mathrm{msec}$ after the tetanus. $B$, Superimposed control EPSC pairs (thin lines) and test pairs taken $500 \mathrm{msec}$ after a tetanus (thick lines). $C$, Control and test pairs scaled to the peak of the first EPSC. Traces are averages of three trials. $D$, Time course of heterosynaptic depression (top) and increase in paired-pulse facilitation (bottom) of the test pair after tetanus. Data points represent averages of three trials each. $\Delta t$ is the time between the tetanus and the test pair of EPSCs. EPSCs were recorded at $-20 \mathrm{mV} . T=32^{\circ} \mathrm{C}$.

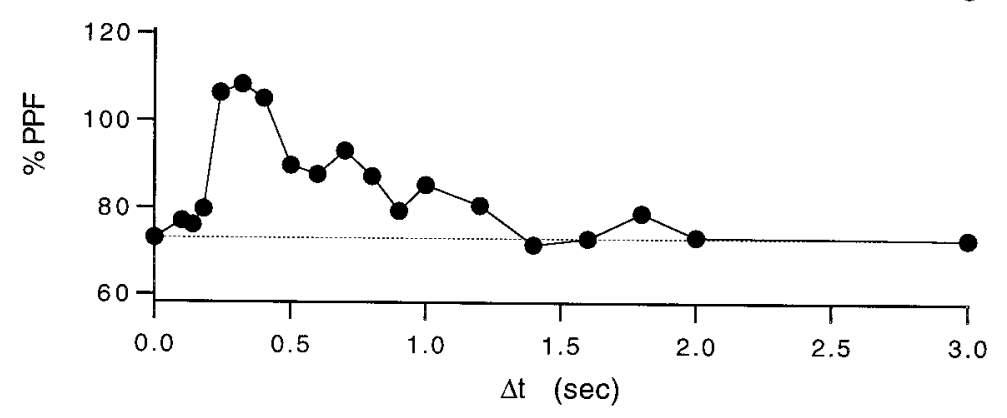

the majority of the presynaptic terminals onto a given Purkinje neuron because of their depth within the slice (see Fig. 2). Because of this complication, the kinetics of uncaged GABA inhibition had a fast component and a slower component caused by GABA diffusing to deeper synapses in the slice. Figure $10 \mathrm{~A}$ shows an example of uncaged GABA on the EPSC magnitude at three time delays after photolysis at $32^{\circ} \mathrm{C}$. Significant synaptic depression can be seen as early as $50 \mathrm{msec}$ after exposure to GABA. As in the case of heterosynaptic depression, the relative amount of PPF increased along with a reduction in the peak of the first EPSC (Fig. 10B).

We primarily used presynaptic calcium influx as an assay for the effects of uncaged GABA. Experiments were performed with labeled parallel fibers that were near the surface of the slice to minimize dilution of the caged GABA (see Fig. 2). The kinetics of the uncaged GABA-induced reduction in presynaptic calcium influx are shown at 24 and $32^{\circ} \mathrm{C}$ (Fig. $11 A, B$ ) for representative experiments and are summarized for a number of experiments in time scale. The reduction in presynaptic calcium rises with a $\tau$ of $180 \mathrm{msec}$ and decays with a $\tau$ of $1.8 \mathrm{sec}$ at $24^{\circ} \mathrm{C}$. At $32^{\circ} \mathrm{C}$, the rise and decay times decreased to 100 and $680 \mathrm{msec}$, respectively. The relatively high $Q_{10}$ (3.3) of the decay kinetics suggests that they are not limited by simple diff usion of free GABA. Both the active uptake of GABA by amino acid transporters and the deactivation kinetics of the calcium channel modulation pathway within the parallel fibers may contribute to this decay time course.

\section{Comparison of heterosynaptic depression to photolysis of caged GABA}

As shown in Figure 12, a comparison of the reduction in stimulusevoked presynaptic calcium influx observed in heterosynaptic inhibition experiments and in experiments in which $\sim 10 \mu \mathrm{M}$ free GABA was uncaged (180 $\mu \mathrm{M}$ caged GABA, diluted to $82 \%, 7.7 \%$ conversion) showed remarkably similar magnitude and kinetics.
Figure $11 C$. The inset shows the early time points on an expanded 


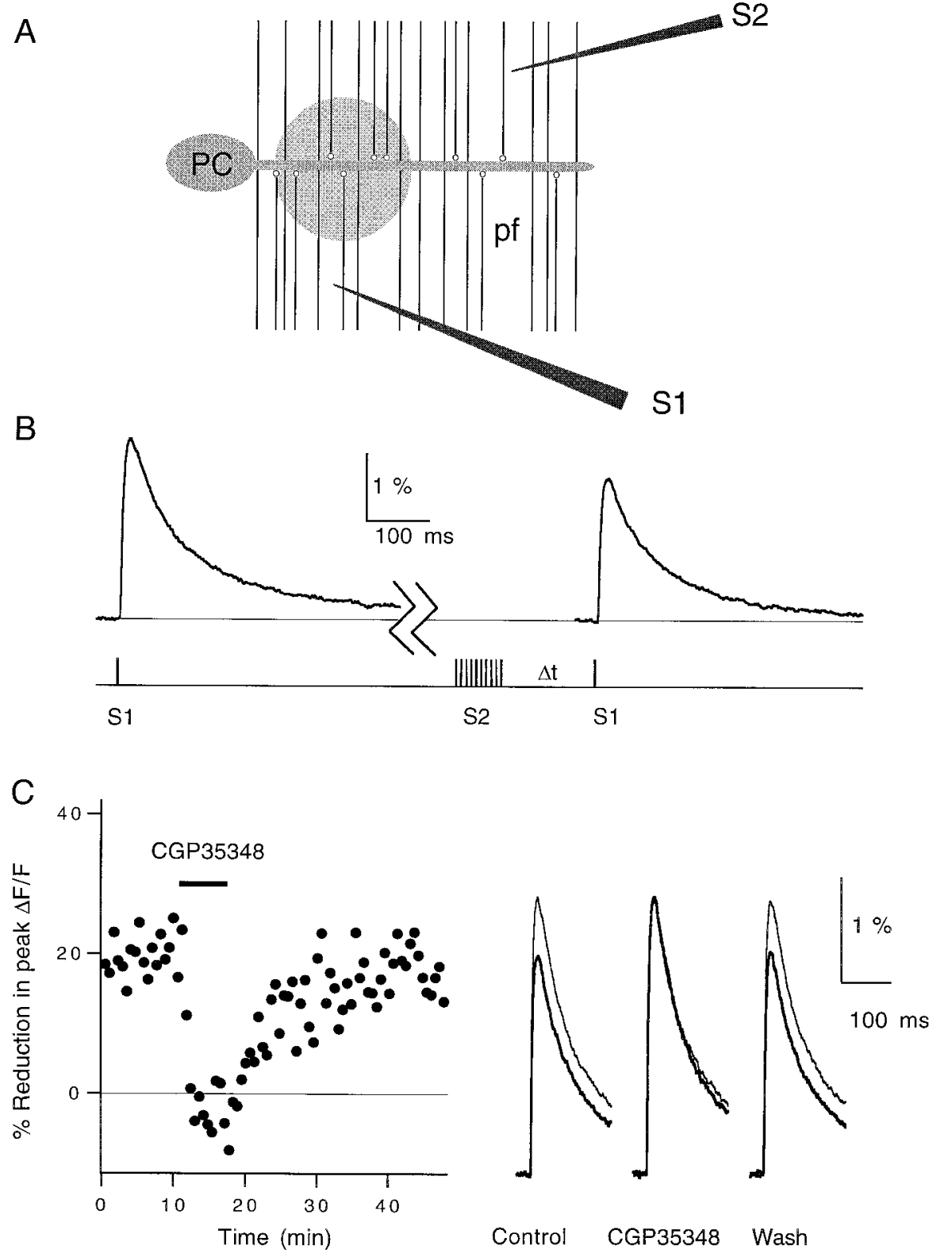

Figure 6. Heterosynaptic reduction in stimulusevoked presynaptic calcium influx. $A$, Cartoon showing the placement of the test electrode $(S 1)$ and the tetanus electrode $(S 2)$ in the molecular layer. Fluorescence measurements were taken from the shaded region of the parallel fibers $(p f)$. $P C$, Purkinje cell. $B$, pulse protocol (bottom) and magnesium green $\Delta F / F$ fluorescence transients (top). Traces are averages of 15 trials. The first transient was evoked by electrode S1 $10 \mathrm{sec}$ before a 10 pulse, $100 \mathrm{~Hz}$ tetanus delivered by S2. The second transient was evoked by electrode S1 600 msec after the tetanus. $C$, Elimination of the posttetanic reduction in calcium influx by $100 \mu \mathrm{M}$ CGP35348 (left). Each data point represents the reduction in the peak $\Delta F / F$ transient evoked by $\mathrm{S} 1$ $600 \mathrm{msec}$ after a tetanus evoked by S2 relative to a control transient evoked by S1 $10 \mathrm{sec}$ before the tetanus. Traces in the right panel are averages of 15 traces each taken before (Control), during (CGP35348), and after (Wash) bath application of the $\mathrm{GABA}_{\mathrm{B}}$ antagonist. Calcium transients taken before the tetanus (thin lines) and $600 \mathrm{msec}$ after the tetanus (thick lines) are superimposed. $T=24^{\circ} \mathrm{C}$.
We have observed previously a slight decrease in fiber excitability in the presence of high steady-state concentrations of baclofen (Dittman and Regehr, 1996). In this study, it is unlikely that changes in fiber excitability contributed a significant amount of the observed depression because the stimulus electrode was placed far from the site of local GABA exposure. In addition, at the equivalent levels of reduction in calcium influx observed here, fiber excitability was not affected in our previous study.

\section{DISCUSSION}

In this study, we found that $\mathrm{GABA}_{\mathrm{B}}$ receptors on parallel fiber presynaptic terminals were transiently activated after stimulation of inhibitory interneurons, resulting in a rapid onset heterosynaptic depression that decayed within a few seconds. By measuring presynaptic calcium influx, we confirmed that the synaptic depression was caused primarily by inhibition of presynaptic calcium channels. We were able to emulate the magnitude and time course of this presynaptic inhibition by briefly exposing the parallel fibers to micromolar levels of GABA using the technique of flash photolysis.
This suggests that stimulation of inhibitory interneurons in the molecular layer caused a brief and widespread elevation in the concentration of extrasynaptic GABA to 5-10 $\mu \mathrm{M}$.

\section{Kinetics of channel modulation}

Calcium and potassium channels are targeted by a variety of modulatory pathways within neurons on multiple time scales (Anwyl, 1991; Jones, 1991; Gage, 1992; Sahara and Westbrook, 1993; Zhou et al., 1997). The rapid modulation of calcium influx observed in our experiments is consistent with a membranedelimited pathway such as G-protein coupling between $\mathrm{GABA}_{\mathrm{B}}$ receptors and ion channels (Hille, 1992). Previously, the kinetics of ion channel modulation has been studied using either synaptic stimulation in brain slices or fast solution exchange in cultured or dissociated neurons. For example, monosynaptic $\mathrm{GABA}_{\mathrm{B}} \mathrm{K}^{+}$ currents recorded at $34-35^{\circ} \mathrm{C}$ in granule cells of the dentate gyrus had an activation time constant of $45 \mathrm{msec}$ and doubleexponential decay time constants of 110 and $516 \mathrm{msec}$ (Otis et al., 1993). In studies using fast solution exchange, the modulation of 
A
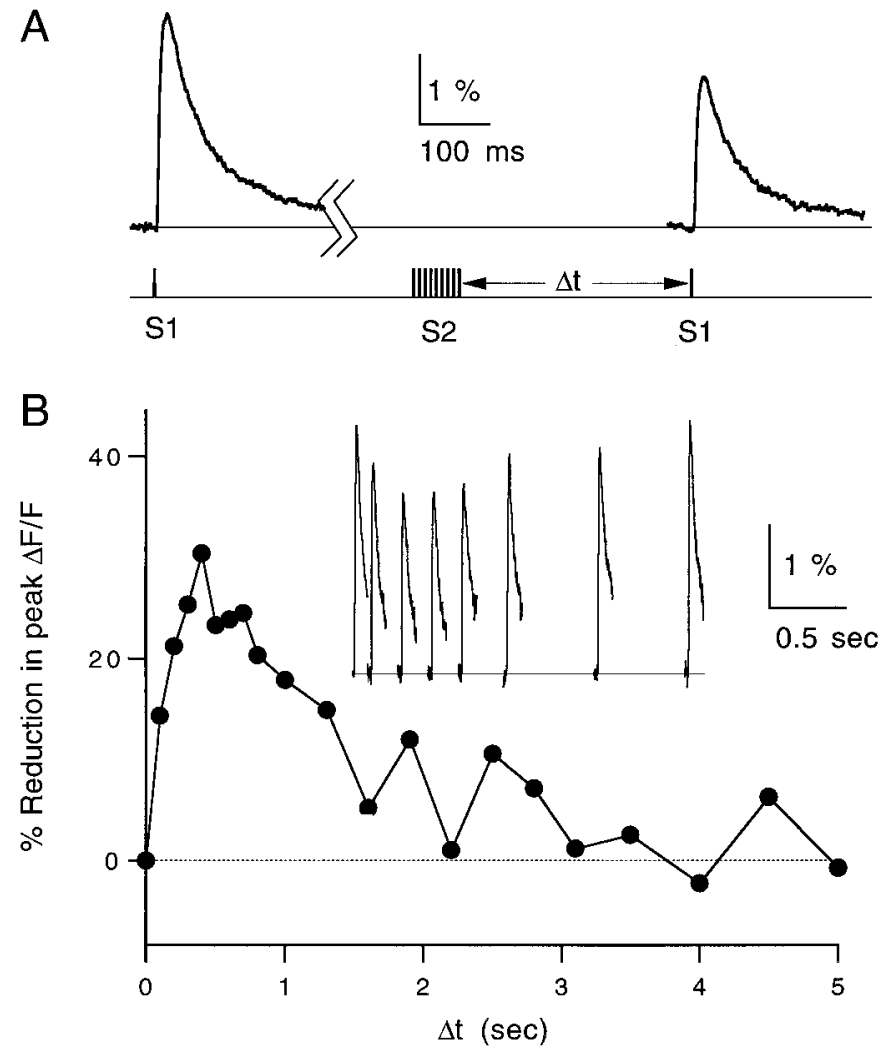

Figure 7. Time course of reduction in presynaptic calcium influx. $A$, Magnesium green $\Delta F / F$ transients (top) and stimulus protocol (bottom) at $32^{\circ} \mathrm{C}$. $B$, Time course of post-tetanic reduction of calcium influx. Each data point represents the relative decrease in the peak $\Delta F / F$ transient evoked by $S 1$ after a tetanus delivered by $S 2$ relative to a control transient evoked by S1 $10 \mathrm{sec}$ before the tetanus. Inset, Fluorescence transients taken at seven different times after tetanus. Traces and data points are averages of three trials. $\Delta t$ is the time between the tetanus and the test pulse.

ion channels by rapid step applications of $\mathrm{GABA}_{\mathrm{B}}$ receptor agonists has been described by a time lag $\left(\Delta t_{\mathrm{on}}\right)$ followed by exponential modulation $\left(\tau_{\text {on }}\right)$ (Pfrieger et al., 1994; Sodickson and Bean, 1996). After rapid agonist removal, there is another lag $\left(\Delta t_{\text {off }}\right)$ followed by an exponential decay $\left(\tau_{\text {off }}\right)$ of modulation. These parameters depend on the concentration of agonist and the duration of application. At room temperature, in acutely dissociated CA3 pyramidal cells, activation of $\mathrm{K}^{+}$channels after application of either GABA or the $\mathrm{GABA}_{\mathrm{B}}$ receptor agonist baclofen is described by the parameters $\Delta t_{\text {on }}, \tau_{\text {on }}, \Delta t_{\text {off }}$, and $\tau_{\text {off }}$ of 50,225 , 150, and $1000 \mathrm{msec}$, respectively (Sodickson and Bean, 1996). In cultured CA3 pyramidal cells at room temperature, inhibition of somatic calcium channels by $50 \mu \mathrm{M}$ baclofen was characterized by the kinetic parameters 130, 220, 700, and $2200 \mathrm{msec}$, respectively (Pfrieger et al., 1994). In parallel fiber presynaptic terminals at $24^{\circ} \mathrm{C}$, we measured a $\tau_{\text {on }}$ of $180 \mathrm{msec}$ after a lag time of $<100$ msec. Our measurement of the time course of decay of inhibition of calcium influx is set in part by the time course of extracellular GABA and also by the kinetics of G-protein-mediated inhibition. We can place an upper limit on $\tau_{\text {off }}$ of $1.8 \mathrm{sec}$ for calcium channel inhibition in parallel fibers at room temperature. Because there are no means of instantly removing extracellular GABA within the slice, we cannot accurately estimate $\Delta t_{\text {off }}$. Thus, at $24^{\circ} \mathrm{C}$ parallel fiber presynaptic terminals have calcium channel modulation parameters of $<100,180,-$, and $\leq 1800 \mathrm{msec}$, respectively.
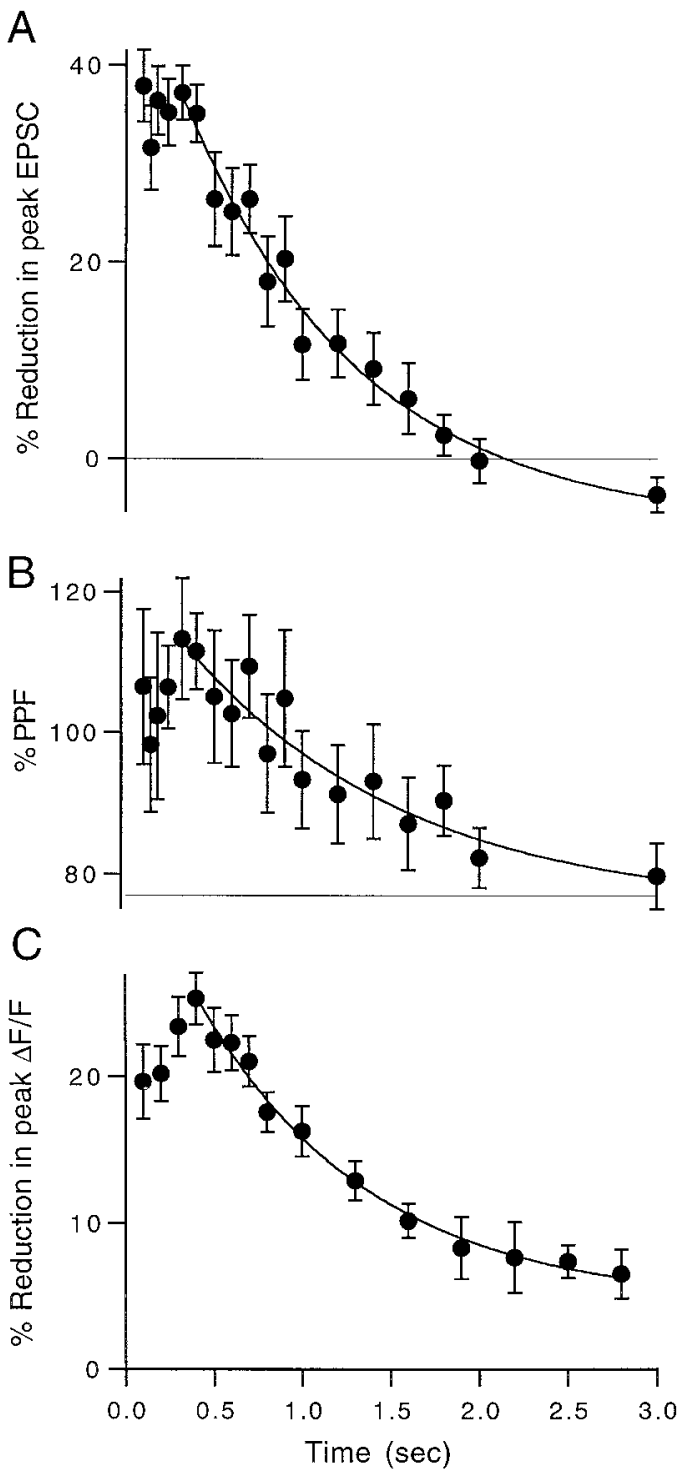

Figure 8. Summary of pre- and postsynaptic time course experiments. $A$, Time course of post-tetanic reduction in EPSC magnitude averaged over $n=7$ experiments performed at $32-33^{\circ} \mathrm{C}$. $B$, Time course of the increase in paired-pulse facilitation of the test EPSCs for the same experiments shown in $A$. $C$, Time course of the reduction in peak $\Delta F / F$ after a tetanus averaged over $n=7$ experiments performed at $32-33^{\circ} \mathrm{C}$. Data points are mean \pm SEM. All three time courses were fit to single-exponential decays (solid lines) with time constants of $1.0,1.25$, and $1.1 \mathrm{sec}$, respectively.

At $32^{\circ} \mathrm{C}$, we observed a marked increase in the speed of calcium channel modulation. Inhibition reached $60 \%$ of its maximal effect within $100 \mathrm{msec}$ (compared with $42 \%$ at $24^{\circ} \mathrm{C}$ ) and increased with a $\tau_{\text {on }}$ of 70-100 msec. The decay of modulation had a $\tau_{\text {off }}$ of 680 msec, giving a $Q_{10}$ of 3.3 for the decay kinetics. Calcium channel modulation parameters at $32^{\circ} \mathrm{C}$ are $\ll 100,70-100,-$, and $\leq 680$ msec, respectively. The high temperature dependence of calcium channel modulation kinetics indicates that the effect of extrasynaptic GABA is not limited by simple diffusion. Both accelerated removal of extracellular GABA and faster modulation kinetics at high temperatures could contribute to this high $Q_{10}$. Furthermore, if the $Q_{10}$ remains high at physiological temperatures, these data imply that channel modulation can occur within $100 \mathrm{msec}$ and decay within $1 \mathrm{sec}$ if extrasynaptic GABA can be cleared rapidly. 
A

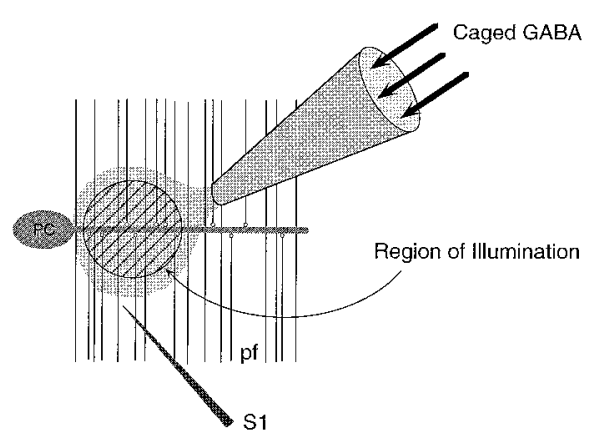

B
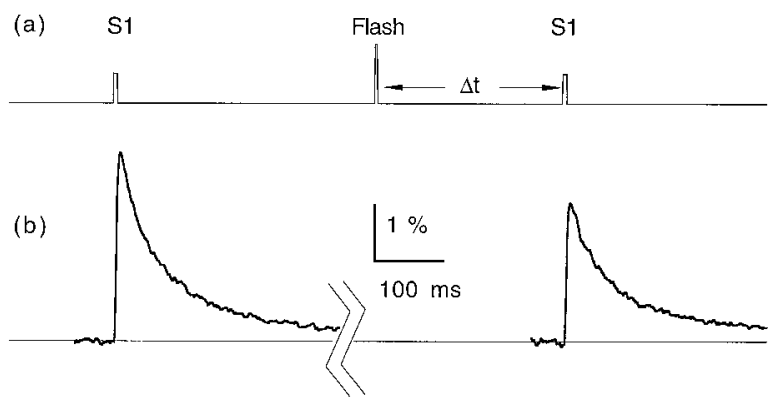

(c)

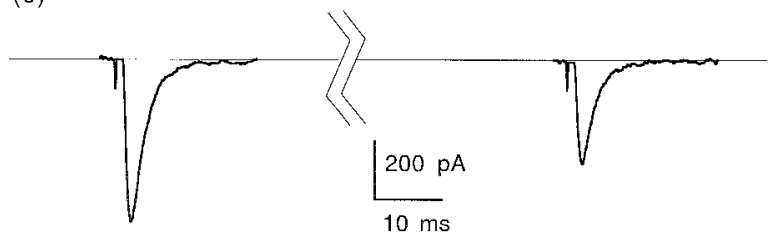

Figure 9. Effects of uncaged GABA on presynaptic calcium influx and EPSC magnitude. $A$, Cartoon describing the placement of the pipette containing caged GABA in the molecular layer. A small spot represented by the hatched circle within the parallel fibers $(p f)$ represents the region exposed to the UV flash. For calcium measurements, this is also the region monitored for fluorescence changes after stimulation by the test electrode (S1). For synaptic physiology experiments, the Purkinje cell $(P C)$ was voltage-clamped to record EPSCs evoked by S1. $B a$, Pulse protocol used for both EPSC and calcium influx measurements and representative experiments showing the effect of uncaged GABA on stimulus-evoked presynaptic calcium influx $(B b)$ and Purkinje cell EPSCs $(B c)$. In both cases, the control trace was evoked $10 \mathrm{sec}$ before the flash and the test trace was evoked $400 \mathrm{msec}$ after the flash. All traces represent averages of three to five trials. EPSCs were recorded at $-40 \mathrm{mV} . T=32^{\circ} \mathrm{C}$.

Surprisingly, the magnitude of modulation was not temperaturedependent over the range of $24-32^{\circ} \mathrm{C}$. It is difficult to interpret this observation because each of the many steps involved in modulation of calcium channels and reuptake of extrasynaptic GABA may have different temperature sensitivities.

\section{Kinetics of modulation of synaptic transmission}

Using steady-state applications of baclofen at room temperature, we have described previously a supralinear power law between presynaptic calcium influx and release of neurotransmitter at this synapse (Dittman and Regehr, 1996) of the following form:

$$
\text { release }=k\left(\mathrm{Ca}_{\text {influx }}\right)^{n} .
$$

Two important consequences of this nonlinearity must be considered when comparing presynaptic calcium to synaptic currents. First, changes in presynaptic calcium influx will result in significantly larger changes in the neurotransmitter release driven by this calcium. For instance, with $n=2$, a 25\% decrease in calcium
A
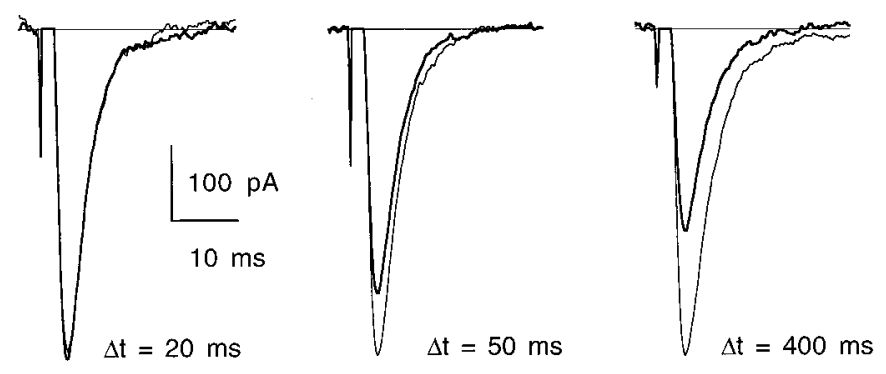

$\mathrm{B}$
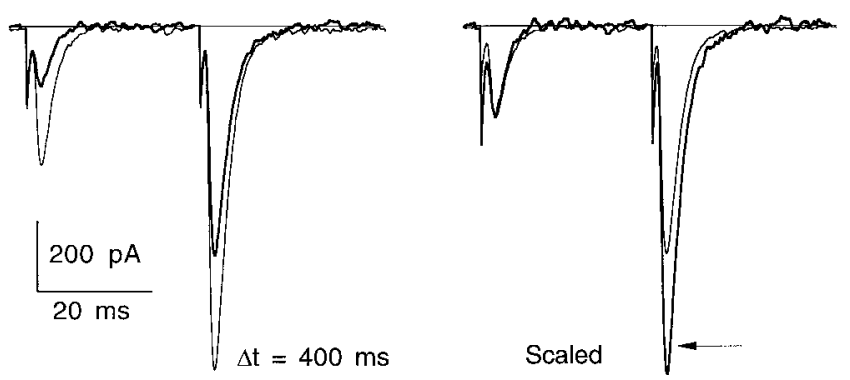

Figure 10. Inhibition of synaptic transmission by uncaged GABA. A, Superimposed traces from control (thin lines) and postphotolysis (thick lines) stimulus-evoked EPSCs for a representative experiment at three delay times after UV flash. Traces are averages of three to four trials. $T=$ $32^{\circ} \mathrm{C}$. B, Left, Paired-pulse facilitation before (thin lines) and $400 \mathrm{msec}$ after UV flash (thick lines). Right, Traces are scaled to the peak of the first EPSC to reveal an increase in PPF (arrow) after exposure to uncaged GABA. Interstimulus interval for PPF was $30 \mathrm{msec}$. Traces are averages of four trials. EPSCs were recorded at $-40 \mathrm{mV} . T=34^{\circ} \mathrm{C}$.

influx would result in a $44 \%$ decrease in release $\left(0.75^{2} \approx 0.56\right)$. Second, as a result of this power law relationship, there will be differences in the modulation kinetics of EPSCs and calcium channels. According to Equation 3, if the modulation transiently reduces calcium influx, the decay of the reduction in EPSC size will lag behind the decay of calcium channel inhibition. On the other hand, if the modulation transiently increases calcium influx, the reverse will be true. In either case, the differences in time courses will be negligible if the absolute amount of calcium channel modulation is small. The onset of calcium channel modulation will appear to lag behind the onset of EPSC reduction when measured by changes in release for a supralinear power law, regardless of the direction of modulation.

The effects of a transient increase in extrasynaptic GABA on calcium influx and release are consistent with the predictions of Equation 3. We found that the average reduction in EPSC size was larger than the corresponding reduction in calcium influx. Furthermore, heterosynaptic depression of the Purkinje cell EPSC and presynaptic inhibition of calcium influx decayed with similar time courses in our experiments. This is in agreement with Pfrieger et al. (1994), who reported nearly identical kinetics for the modulation of somatic calcium channels and for modulation of synaptic transmission in hippocampal cultures using baclofen.

Photolysis of caged GABA confirmed the rapid onset of modulation. Uncaged GABA significantly reduced the peak EPSC within $50 \mathrm{msec}$ at $32^{\circ} \mathrm{C}$ and maximally suppressed synaptic transmission within 300-400 msec. However, photolysis experiments were not informative with respect to the relative reductions of 

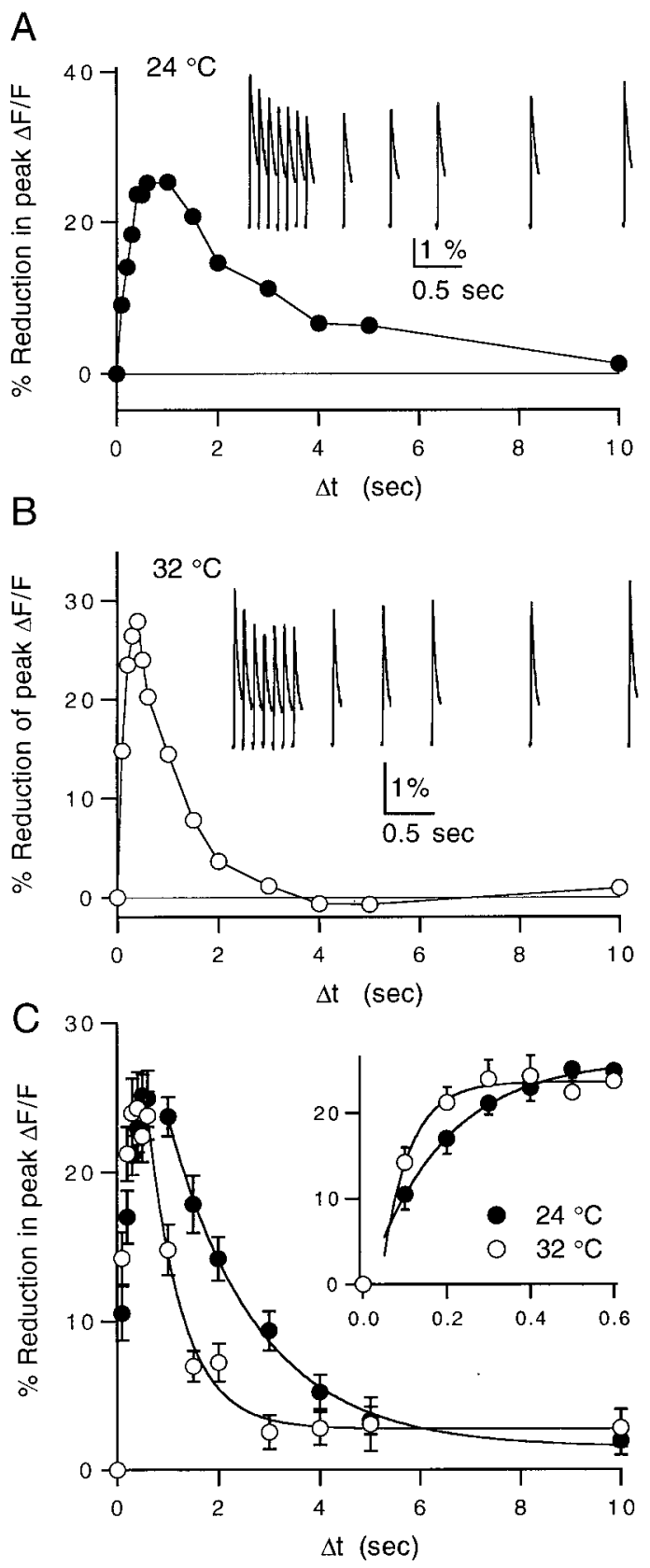

Figure 11. Reduction in presynaptic calcium influx by uncaged GABA at 24 and $32^{\circ} \mathrm{C}$. $A$, Representative example of a caged GABA experiment performed at $24^{\circ} \mathrm{C}$ measuring the time course of reduction in calcium influx after photolysis of caged GABA. Inset, $\Delta F / F$ signals after the UV flash. Data points and traces are averages of three trials. $B$, Example of a similar experiment performed at $32^{\circ} \mathrm{C}$. Inset, $\Delta F / F$ signals after the UV flash. $C$, Averages of 10 experiments at $24^{\circ} \mathrm{C}$ ( filled circles) and 9 experiments at $32^{\circ} \mathrm{C}$ (open circles). Falling phases are fit by single-exponential decays with time constants of $1.77 \mathrm{sec}$ at $24^{\circ} \mathrm{C}$ and $0.68 \mathrm{sec}$ at $32^{\circ} \mathrm{C}$. Inset, Rising phase of the reduction in calcium influx after photolysis shown on an expanded time scale. The onset was fit to a single exponential in both cases with time constants of $184 \mathrm{msec}$ at $24^{\circ} \mathrm{C}$ and $70 \mathrm{msec}$ at $32^{\circ} \mathrm{C}$. Data points are given as mean \pm SEM.

calcium influx and EPSC size due to dilution of caged GABA deeper in the slice (see Materials and Methods).

It is reasonable to assume that, at physiological temperatures, the time window in which a pulse of GABA can inhibit synaptic transmission will be even faster than at $32^{\circ} \mathrm{C}$. Synaptic depression

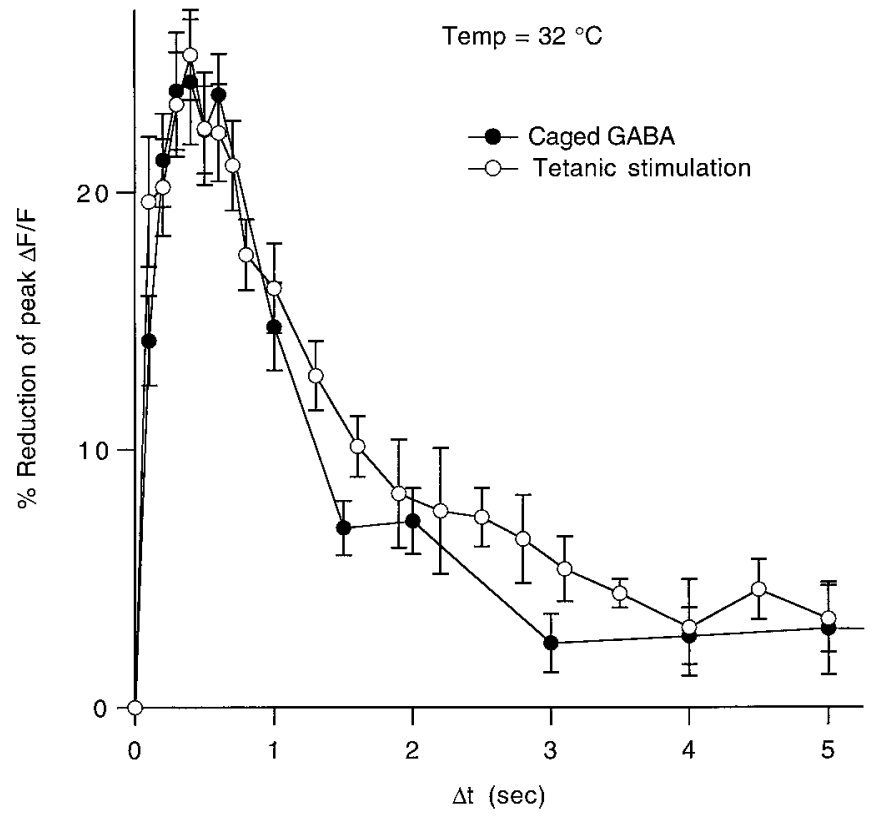

Figure 12. Time course of reduction in presynaptic calcium influx caused by heterosynaptic depression versus uncaged GABA. The averages of both the post-tetanic and the photolysis-induced reductions in calcium influx at $32^{\circ} \mathrm{C}$ are superimposed to compare relative magnitudes and time courses. Data points are given as mean \pm SEM.

should appear tens of milliseconds after increases in extrasynaptic GABA, and decay should appear in a few hundred milliseconds.

\section{Probing kinetics of modulation using photolysis of caged neurotransmitters}

Caged neurotransmitters have been used to investigate a variety of cellular and circuit level processes in brain slices such as neurotransmitter reuptake (Lee et al., 1996) and synaptic connectivity (Katz and Dalva, 1994). In these studies, the technique of photolysis proved to be of great benefit because rapid application of neurotransmitters within a small region of the slice by conventional techniques is not possible. These same benefits should also make photolysis a useful technique in the analysis of modulation kinetics. However, there are limitations to the amount of caged compound that can be used. There is typically a baseline uncaged activity of 1-2\% due to spontaneous uncaging and impure stocks of caged compound, so high concentrations of caged neurotransmitters are likely to activate high-affinity receptors before UV exposure. Also, there are limits to the fraction of caged compound that undergoes conversion after exposure to light because of their relatively low quantum efficiencies and extinction coefficients (McCray and Trentham, 1989). Despite these shortcomings, flash photolysis will make rapid, localized control of chemical concentration in brain slices practical for many applications.

\section{Role of heterosynaptic depression in synaptic transmission}

Because of the high affinity of presynaptic metabotropic receptors and the rapid kinetics of channel modulation at the parallel fiber presynaptic terminal, synaptic transmission at the granule cell to Purkinje cell synapse is exquisitely sensitive to the activity of neighboring inhibitory interneurons. The experiments described here suggest that, under physiological conditions, brief periods of activity in one set of parallel fibers can rapidly influence the 
efficacy of a separate group of parallel fiber synapses via activation of stellate and basket cells within the molecular layer.

Feedforward inhibition provided by stellate and basket cells is thought to be important in the proper functioning of the cerebellar cortical circuit (Marr, 1969; Albus, 1971). Eccles and others have postulated a role for stellate and basket cells in forming a lateral inhibitory region surrounding a beam of activated parallel fibers (Eccles et al., 1966, 1967). This inhibition was expressed at the level of inhibitory synapses onto Purkinje cells spreading for hundreds of micrometers lateral to the active parallel fibers. The heterosynaptic depression described here may contribute to lateral inhibition via an entirely different mechanism. GABA released by activated stellate and basket cells may transiently suppress granule cell to Purkinje cell synapses over an extensive region neighboring the active parallel fibers, thereby sharpening surround inhibition. This presynaptic depression may also have a longer duration than direct Purkinje cell inhibition by $\mathrm{GABA}_{\mathrm{A}}$ receptor activation, depending on the lifetime of extrasynaptic GABA and the deactivation kinetics of the modulatory pathway. In addition, multiple types of $\mathrm{GABA}_{\mathrm{B}}$ receptors with various affinities, kinetics, and coupling to calcium and potassium channels may be present in cerebellar cortex (Bonanno and Raiteri, 1992; Bonanno and Raiteri, 1993; Guyon and Leresche, 1995; Kaupmann et al., 1997). Segregation of these receptors between pre- and postsynaptic elements as well as differential expression on presynaptic terminals of parallel fibers and interneurons can expand further the repertoire of cellular responses to extrasynaptic GABA.

\section{REFERENCES}

Albus JS (1971) A theory of cerebellar function. Math Biosci 10:25-61. Anwyl R (1991) Modulation of vertebrate neuronal calcium channels by transmitters. Brain Res Rev 16:265-281.

Bonanno G, Raiteri M (1992) Functional evidence for multiple GABA $_{B}$ receptor subtypes in the rat cerebral cortex. J Pharmacol Exp Ther 262:114-118.

Bonanno G, Raiteri M (1993) Multiple GABA ${ }_{B}$ receptors. Trends Pharmacol Sci 14:259-261.

Davies CH, Davies SN, Collingridge GL (1990) Paired-pulse depression of monosynaptic GABA-mediated inhibitory postsynaptic responses in rat hippocampus. J Physiol (Lond) 424:513-531.

Davies CH, Pozza MF, Collingridge GL (1993) CGP 55845A: a potent antagonist of $\mathrm{GABA}_{\mathrm{B}}$ receptors in the $\mathrm{CA} 1$ region of rat hippocampus. Neuropharmacology 32:1071-1073.

Deisz RA, Prince DA (1989) Frequency-dependent depression of inhibition in guinea-pig neocortex in vitro by $\mathrm{GABA}_{\mathrm{B}}$ receptor feed-back on GABA release. J Physiol (Lond) 412:513-541.

Dittman JS, Regehr WG (1996) Contributions of calcium-dependent and calcium-independent mechanisms to presynaptic inhibition at a cerebellar synapse. J Neurosci 16:1623-1633.

Eccles JC, Ito M, Szentagothai J (1967) The cerebellum as a neuronal machine. New York: Springer.

Eccles JC, LLinas R, Sasaki K (1966) The inhibitory interneurones within the cerebellar cortex. Exp Brain Res 1:1-16.

Fuxe K, Agnati LF (1991) Volume transmission in the brain: novel mechanisms for neural transmission. New York: Raven.

Gage PW (1992) Activation and modulation of neuronal $\mathrm{K}^{+}$channels by GABA. Trends Neurosci 15:46-51.

Gee KR, Wieboldt R, Hess GP (1994) Synthesis and photochemistry of a new photolabile derivative of GABA. Neurotransmitter release and receptor activation in the microsecond time region. J Am Chem Soc 116:8366-8367.

Guyon A, Leresche N (1995) Modulation by different GABA ${ }_{B}$ receptor types of voltage-activated calcium currents in rat thalamocortical neurones. J Physiol (Lond) 485:29-42.

Herrington J, Bookman RJ (1995) Pulse control V4.5: IGOR XOPs for patch clamp data acquisition. Miami: University of Miami.

Hille B (1992) Ionic channels of excitable membranes, 2nd Ed. Sunderland, MA: Sinauer.
Isaacson JS, Solis JM, Nicoll RA (1993) Local and diffuse synaptic actions of GABA in the hippocampus. Neuron 10:165-175.

Ito M (1984) The cerebellum and neural control. New York: Raven.

Jones SW (1991) Time course of receptor-channel coupling in frog sympathetic neurons. Biophys J 60:502-507.

Katz LC, Dalva MB (1994) Scanning laser photostimulation: a new approach for analyzing brain circuits. J Neurosci Methods 54:205-218.

Kaupmann K, Huggel K, Held J, Flor P, Bischoff S, Mickel S, McMaster G, Angst C, Bittiger H, Froestl W, Bettler B (1997) Expression cloning of $\mathrm{GABA}_{\mathrm{B}}$ receptors uncovers similarity to metabotropic glutamate receptors. Nature 386:239-246.

Lee TH, Gee KR, Ellinwood EH, Seidler FJ (1996) Combining "cageddopamine" photolysis with fast-scan cyclic voltammetry to assess dopamine clearance and release autoinhibition in vitro. J Neurosci Methods 67:221-231.

Lerma J, Herranz AS, Herreras O, Abraira V, Martin Del Rio R (1986) In vivo determination of extracellular concentration of amino acids in the rat hippocampus. A method based on brain dialysis and computerized analysis. Brain Res 384:145-155.

Marr D (1969) A theory of cerebellar cortex. J Physiol (Lond) 202:437-470.

McCray JA, Trentham DR (1989) Properties and uses of photoreactive caged compounds. Annu Rev Biophys Chem 18:239-270.

Mintz IM, Sabatini BL, Regehr WG (1995) Calcium control of transmitter release at a cerebellar synapse. Neuron 15:675-688.

Mody I, De Koninck Y, Otis TS, Soltesz I (1994) Bridging the cleft at GABA synapses in the brain. Trends Neurosci 17:517-525.

Nicoll RA, Malenka RM, Kauer JA (1990) Functional comparison of neurotransmitter receptor subtypes in mammalian central nervous system. Physiol Rev 70:513-565.

Olpe HR, Karlsson G, Pozza MF, Brugger F, Steinmann M, Van Riezen H, Fagg G, Hall RG, Froestl W, Bittiger H (1990) CGP 35348: a centrally active blocker of $\mathrm{GABA}_{\mathrm{B}}$ receptors. Eur J Pharmacol 187:27-38.

Otis TS, DeKoninck Y, Mody I (1993) Characterization of synaptically elicited $\mathrm{GABA}_{\mathrm{B}}$ responses using patch-clamp recordings in rat hippocampal slices. J Physiol (Lond) 463:391-407.

Pekhletski R Gerlai R, Overstreet L, Huang X, Agopyan N, Slater N, Abramow-Newerly W, Roder J, Hampson D (1996) Impaired cerebellar synaptic plasticity and motor performance in mice lacking the mGluR4 subtype of metabotropic glutamate receptor. J Neurosci 16:6364-6373.

Pfrieger FW, Gottmann K, Lux HD (1994) Kinetics of $\mathrm{GABA}_{\mathrm{B}}$ receptor-mediated inhibition of calcium currents and excitatory synaptic transmission in hippocampal neurons in vitro. Neuron 12:97-107.

Regehr WG, Atluri PP (1995) Calcium transients in cerebellar granule cell presynaptic terminals. Biophys J 68:2156-2170.

Regehr WG, Tank DW (1991) Selective fura-2 loading of presynaptic terminals and nerve cell processes by local perfusion in mammalian brain slice. J Neurosci Methods 37:111-119.

Sahara Y, Westbrook G (1993) Modulation of calcium currents by a metabotropic glutamate receptor involves fast and slow kinetic components in cultured hippocampal neurons. J Neurosci 13:3041-3050.

Scholz KP, Miller RJ (1991) GABA $_{\mathrm{B}}$ receptor-mediated inhibition of $\mathrm{Ca}^{2+}$ currents and synaptic transmission in cultured rat hippocampal neurones. J Physiol (Lond) 444:669-686.

Sodickson DL, Bean BP (1996) GABA $_{B}$ receptor-activated inwardly rectifying potassium current in dissociated hippocampal CA3 neurons. J Neurosci 16:6374-6385.

Starke K (1981) Presynaptic receptors. Annu Rev Pharmacol Toxicol 21:7-30.

Walker JW, Reid GP, McCray JA, Trentham DR (1988) Photolabile 1-(2-nitrophenyl)ethyl phosphate esters of adenine nucleotide analogues. Synthesis and mechanism of photolysis. J Am Chem Soc 110:7170-7177.

Wu L-G, Saggau P (1994) Adenosine inhibits evoked synaptic transmission primarily by reducing presynaptic calcium influx in area CA1 of hippocampus. Neuron 12:1139-1148.

Yawo H, Chuhma N (1993) Preferential inhibition of $\omega$-conotoxinsensitive presynaptic $\mathrm{Ca}^{2+}$ channels by adenosine autoreceptors. Nature 365:256-258.

Zhou J, Shapiro MS, Hille B (1997) Speed of $\mathrm{Ca}^{2+}$ channel modulation by neurotransmitters in rat sympathetic neurons. J Neurophysiol 77:2040-2048.

Zucker RS (1989) Short-term synaptic plasticity. Annu Rev Neurosci 12:13-31. 